\title{
Nonlinear earthquake behaviour of highway tunnels
}

\author{
B. Sevim \\ Gümüşhane University, Department of Civil Engineering, 29000, Gümüşhane, Turkey
}

Received: 14 August 2011 - Revised: 12 September 201 - Accepted: 15 September 2011 - Published: 13 October 2011

\begin{abstract}
This paper describes the Arhavi Highway Tunnel which has two tubes, its geometrical properties, finite element model, and the nonlinear earthquake behaviour under a huge ground motion considering soil-structure interaction. The Arhavi Highway Tunnel is one of the tallest tunnels constructed in the Black Sea region of Turkey as part of the Coast Road Project. The tunnel has two tubes and each of them is about $1000 \mathrm{~m}$ tall. In the study, the modal analyses of the tunnel considering soil-structure interaction are performed and natural frequencies and mode shapes are obtained. Then, nonlinear transient analysis of the tunnel using Drucker-Prager criteria is performed applying acceleration components of 1992 Erzincan, Turkey earthquake's ground motion. In the time history analyses, Rayleigh damping coefficients are calculated using main natural frequency obtained from modal analysis. Element matrices are computed using the Gauss numerical integration technique. The Newmark method is used in the solution of the equation of motion. Because too much memory for the analyses is required, the first $7.5 \mathrm{~s}$ of the ground motions, which is the most effective duration, is taken into account in calculations. The displacement and stress results are observed to be the allowable level of the concrete material.
\end{abstract}

\section{Introduction}

Highway tunnels as underground facilities are an integral part of the infrastructure of modern society. They are built in areas subject to earthquake activity and must withstand both seismic and static loading. The highway tunnels have features that make their seismic behaviour distinct from most surface structures. Hovewer, some highway tunnels have

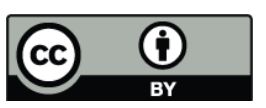

Correspondence to: B. Sevim (bsevim18@hotmail.com) experienced significant damage in recent large earthquakes, including the 1995 Kobe, Japan earthquake, the 1999 ChiChi, Taiwan earthquake and the 1999 Kocaeli, Turkey earthquake (Hashash et al., 2001). Therfore, the determination of seismic behaviour of these underground structures may have importance for researchers (Asakura et al., 2000; Amberg and Russo, 2001; Lanzano et al., 2001).

Earthquake effects on underground structures can be grouped into two categories: ground shaking, ground failure such as liquefaction, fault displacement, and slope instability. Ground shaking refers to the deformation of the ground produced by seismic waves propagating through the Earth's crust. The major factors influencing shaking damage include: the shape, dimensions and depth of the structure; the properties of the, 1987; Hashash et al., 2001). The earthquakes can endanger tunnels and other structures if they are buried in loose, water-saturated soil that can be liquefied by dynamic excitation. Liquefaction implies a drastic loss of shear strength, the consequence of which can be large displacements of structures. Countermeasures are stone columns or soil improvement by densification or grouting (Kolymbas, 2005).

In the early days of FEM applications in tunnelling, computers had a very limited memory. Thus, the management of data was the most important issue, whilst the choice of the appropriate constitutive equation was considered of minor importance. This attitude has survived until our days and one can observe cases of numerical simulation where the used constitutive equation is not even mentioned. This is by no means justified. The use of the proper constitutive equation is of decisive importance. True, the behaviour of soil and rock is extremely complex and, therefore, realistic constitutive equations can be complex to such an extension that they can not be used (Kolymbas, 2005; Cheng et al., 2007; Mroueh and Shahrour, 2008). Nowadays, computer skills have been increaed. This gives a chance to obtain realistic models. A nonlinear procedure is required to assess the

Published by Copernicus Publications on behalf of the European Geosciences Union. 


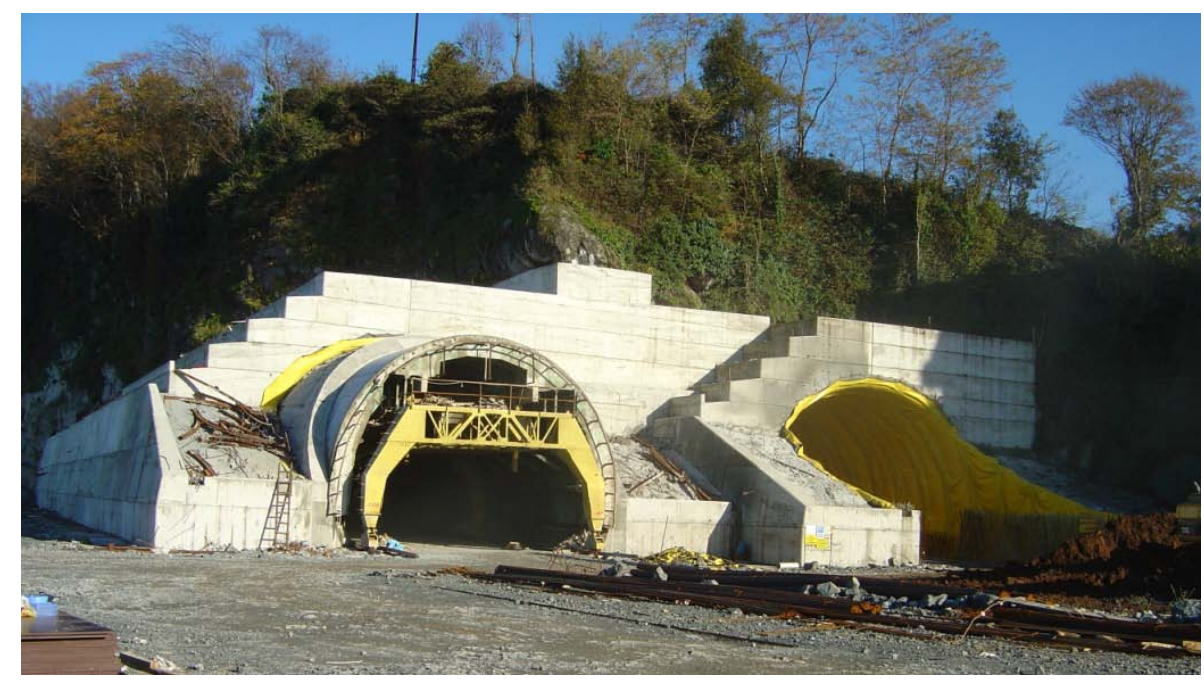

Fig. 1. A photograph of the Arhavi Highway Tunnel.

Table 1. Material properties of the Arhavi Highway Tunnel.

\begin{tabular}{lllll}
\hline \multirow{2}{*}{ Material } & & \multicolumn{3}{c}{ Properties } \\
\cline { 3 - 5 } & Element & $\begin{array}{l}\text { Elasticity } \\
\text { Modulus } \\
\left(\mathrm{N} \mathrm{m}^{-2}\right)\end{array}$ & $\begin{array}{l}\text { Poisson } \\
\text { Ratio } \\
(-)\end{array}$ & $\begin{array}{l}\text { Mass } \\
\text { Density } \\
\left(\mathrm{kg} \mathrm{m}^{-3}\right)\end{array}$ \\
\hline Reinforced Concrete & PLANE42 & $3.00 \mathrm{E} 10$ & 0.2 & 2500 \\
Shotcrete Concrete & PLANE42 & $2.75 \mathrm{E} 10$ & 0.2 & 2400 \\
Rock & PLANE42 & $3.00 \mathrm{E} 10$ & 0.2 & - \\
\hline
\end{tabular}

dynamic behavior of the engineering structures realistically. Many damage criteria are available for the determination of the yield surface or the yield function of materials for nonlinear finite element analysis. The Drucker-Prager criterion is widely used for frictional materials such as rock, concrete and masonry. Drucker and Prager (1952) also obtained a convenient yield function to determine elasto-plastic behaviour of concrete, known as the smoothing Mohr-Coulomb criterion (Drucker and Prager, 1952). This criterion is defined as:

$f=\alpha I_{1}+\sqrt{J_{2}}-k$

In Eq. (1), $I_{1}$ is the first invariant of stress tensor, and $J_{2}$ is the second invariant of deviatoric stress tensor. $\alpha$ and $k$ are constants which depend on cohesion $(c)$ and angle of internal friction $(\phi)$ of the material given in Eq. (2) (Drucker and Prager, 1952; Chen and Mizuno, 1990).

$$
\begin{gathered}
\alpha=\frac{2 \operatorname{Sin} \phi}{\sqrt{3}(3-\operatorname{Sin} \phi)} \\
k=\frac{6 c \operatorname{Cos} \phi}{\sqrt{3}(3-\operatorname{Sin} \phi)}
\end{gathered}
$$

This paper investigates nonlinear earthquake behaviour of a particular highway tunnel, Arhavi, which has two tubes. In the paper, the Arhavi Highway Tunnel and its geometry are first described. After that, the finite element model of the tunnel is modelled using ANSYS software considering soilstructure interaction. Lastly, the nonlinear earthquake behaviour of the tunnel considering Drucker-Prager criteria is investigated applying the 1992 Erzincan, Turkey earhquake's ground motion records.

\section{Description of the Arhavi Highway Tunnel}

The Arhavi Highway Tunnel is one of the tallest tunnels constructed in the Black Sea region of Turkey, as part of the Coast Road Project. The tunnel is located in Arhavi in Artvin, Turkey. It has two tubes and each of them is about $1000 \mathrm{~m}$ tall. One of the photographs of the tunnel appears in Fig. 1. The tunnel has been used for the traffic since 2006.

The Arhavi Highway Tunnel was constructed using New Austrian Tunnelling Method. The rock quality classification was listed based on geological data. The studies show that the rocks had been constituted 70-110 million yr before in Mesozoic time (Satır, 2007). 


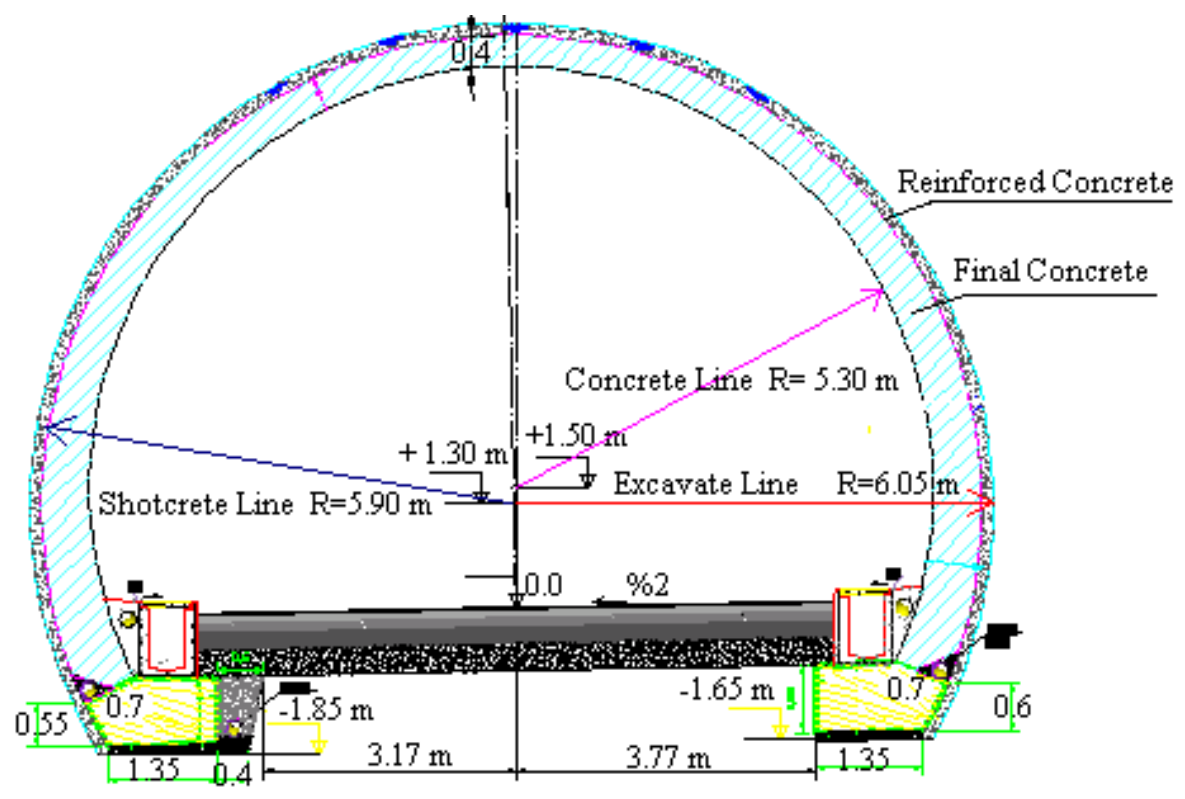

Fig. 2. Geometrical properties of the Arhavi Highway Tunnel (Cengiz Project, 2006).
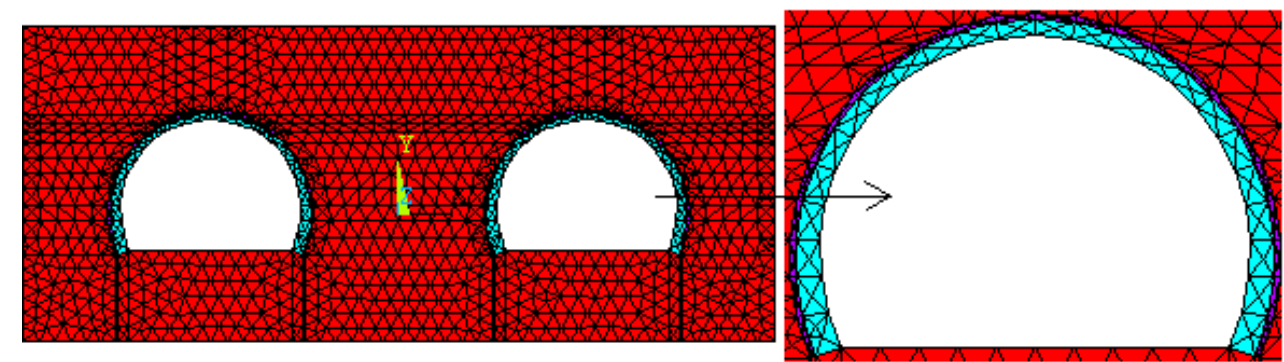

Fig. 3. TheFEM of the Arhavi Highway Tunnel.

\section{Nonlinear earthquake behaviour of the Arhavi Highway Tunnel}

The studies of the Arhavi Highway Tunnel involve its finite element modal analysis and finite element earthquake analyses. The geometrical properties of the Arhavi Highway Tunnel appear in Fig. 2. The tunnel has two tubes and each tube includes reinforced concrete and shotcrete concrete. The radius of each tunnel is $5.3 \mathrm{~m}$. The constant thickness of the shotcrete concrete is $0.15 \mathrm{~m}$. However, the thickness of the concrete is changeable. It has a thickness of $0.4 \mathrm{~m}$ at the top of the tunnel, but the thickness increases through the base and it has $0.7 \mathrm{~m}$ thickness at the road level.

A Finite Element Model (FEM) of the tunnel is constituted using ANSYS (2010) software. 2497 PLANE42 elements are used in the FEM of the tunnel. The element can be used either as a plane element (plane stress or plane strain) or as an axisymmetric element. The element is defined by four nodes having two degrees of freedom at each node: translations in the nodal $\mathrm{x}$ and $\mathrm{y}$ directions. The element has plasticity, creep, swelling, stress stiffening, large deflection, and large strain capabilities. The FEM of the tunnel appears in Fig. 3.

Three main materials, reinforced concrete, shotcrete concrete, and rock are considered in the analyses. The material properties used in the analyses are summarized in Table 1 (Cengiz Project, 2006; G.D.H., 2006; Satır, 2007). The tunnel foundation is assumed as massless. Because of the massless foundation, the analyses considered only the effects of the foundation flexibility. So, the foundation model extended to a distance beyond which its effects on deflections and natural frequencies of the tunnel become negligible (USACE, 2003). As boundary conditions, all of the degrees of freedoms on the four sides of the foundation are fixed. 


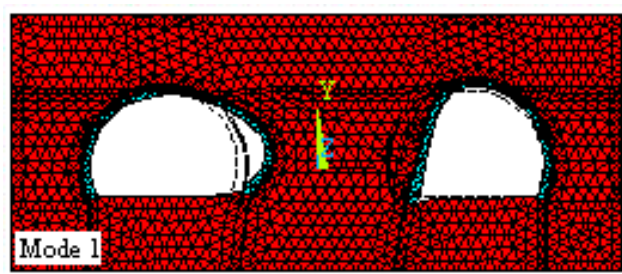

$\mathrm{f}_{\mathrm{l}}=224 \mathrm{~Hz}$

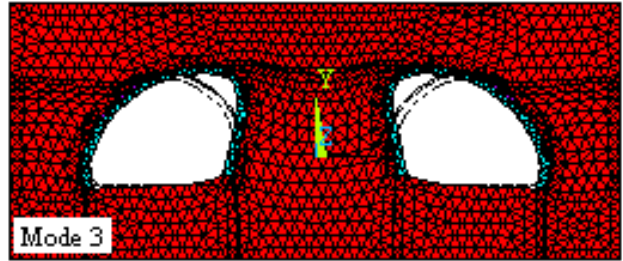

$\mathrm{f}_{3}=290 \mathrm{~Hz}$

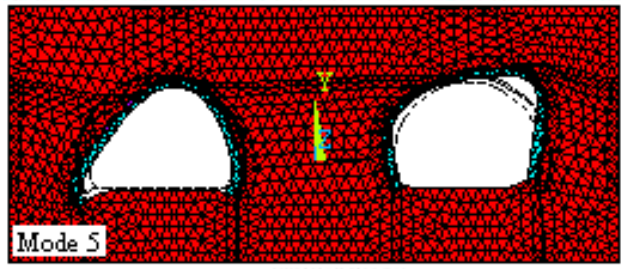

$\mathrm{f}_{\mathrm{s}}=305 \mathrm{~Hz}$

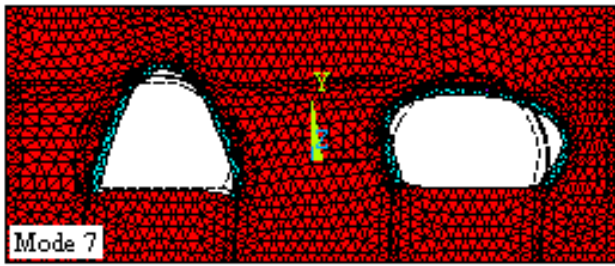

$\mathrm{f}_{7}=318 \mathrm{~Hz}$

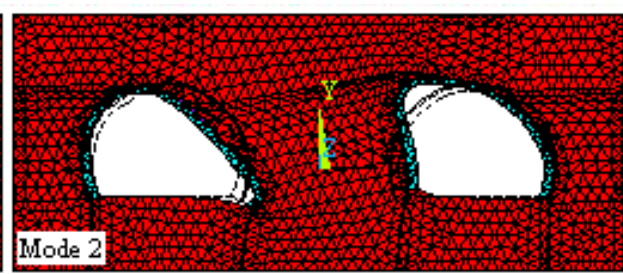

$\mathrm{f}_{2}=281 \mathrm{~Hz}$

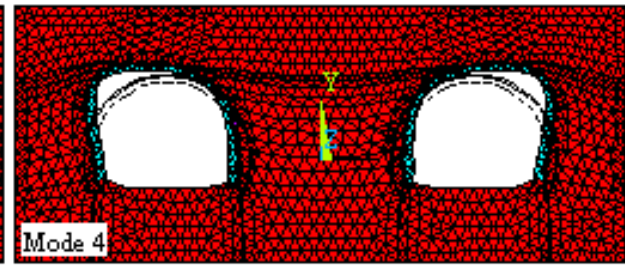

$\mathrm{f}_{\mathrm{t}}=300 \mathrm{~Hz}$

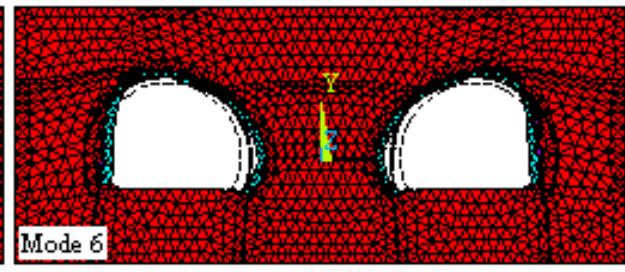

$\mathrm{f}_{\mathrm{i}}=315 \mathrm{~Hz}$

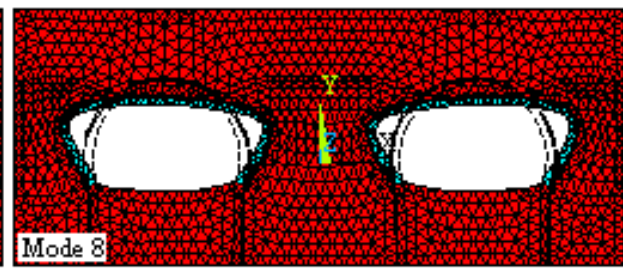

$\mathrm{f}_{\mathrm{z}}=320 \mathrm{~Hz}$

Fig. 4. The mode shapes of the Arhavi Highway Tunnel.

\subsection{Modal Characteristics of the Arhavi Highway Tunnel}

Figure 4 shows the natural frequencies and the mode shapes of the Arhavi Highway Tunnel. As it is seen in Fig. 4, the mode shapes are related to the main concrete of the tunnel. It is not to be wrong to class them as bending modes from Fig. 4.

\subsection{Nonlinear Earthquake Behaviour of the Arhavi Highway Tunnel}

The nonlinear transient analyses of the tunnel are performed considering ERZIKAN/ERZ-NS and ERZIKAN/ERZ-UP components of the 1992 Erzincan ground motion as the excitation sources. This earthquake event occurred in the North Anatolian Fault, which is the nearest fault to the tunnel. The components of the earthquakes appear in Fig. 5 (PEER, 2010). The reason for using these two components is to simulate the realistic behaviour of the earthquake.
The Drucker-Prager damage criterion is preferable for introducing the nonlinear behavior of concrete to the finite element model as its smooth failure surface provides very definite analytical and computational advantages (Barla et al., 2008). The two nonlinear Cohesion (c) and Friction angle $(\Phi)$ material parameters were selected from the literature. $\mathrm{c}=0.61 \mathrm{MPa}, \Phi=28^{\circ}$ are assumed (Barla et al., 2008) for the concrete material.

The element matrices are computed using the Gauss numerical integration technique (Bathe, 1996) in the analyses. The Newmark method is used in the solution of the equation of motion. Because of the computational demand of this method, only the first $7.5 \mathrm{~s}$ of the ground motions, which is the most effective duration, are considered during calculations (Fig. 5). Because the damping ratios are unknown, the author estimates the Rayleigh damping coefficients for an assumed $5 \%$ damping ratio, and Rayleigh damping coefficients are calculated using the first eight natural frequency values obtained from modal analysis. 


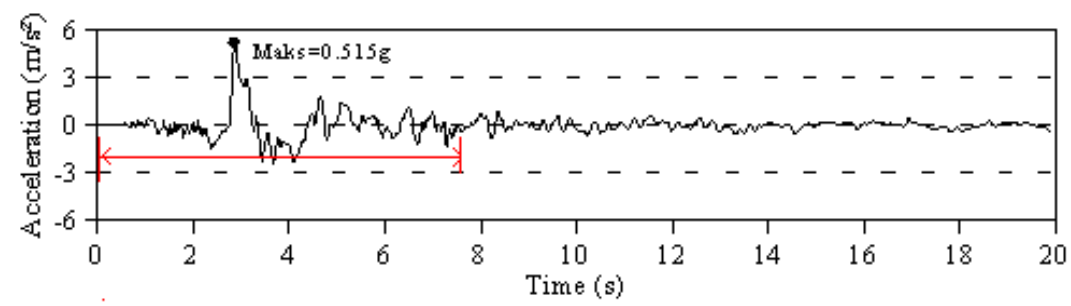

(a) ERZIKAN/ERZ-NS component

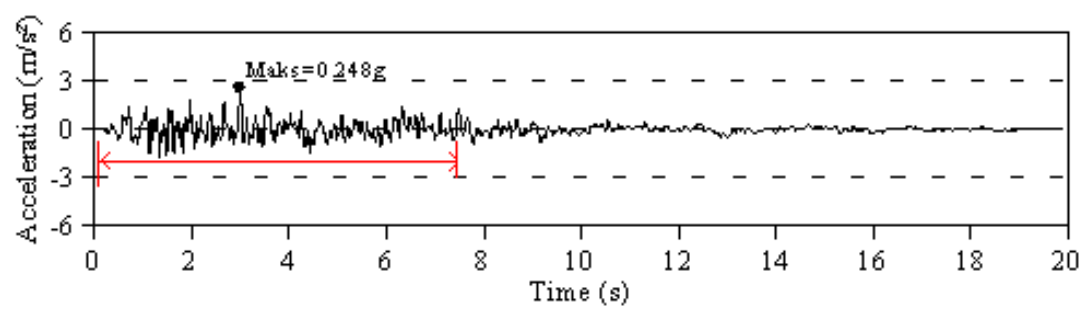

(b) ERZIKAN/ERZ-UP component

Fig. 5. The time histories of ground motion accelerations of 1992 Erzincan earthquake.

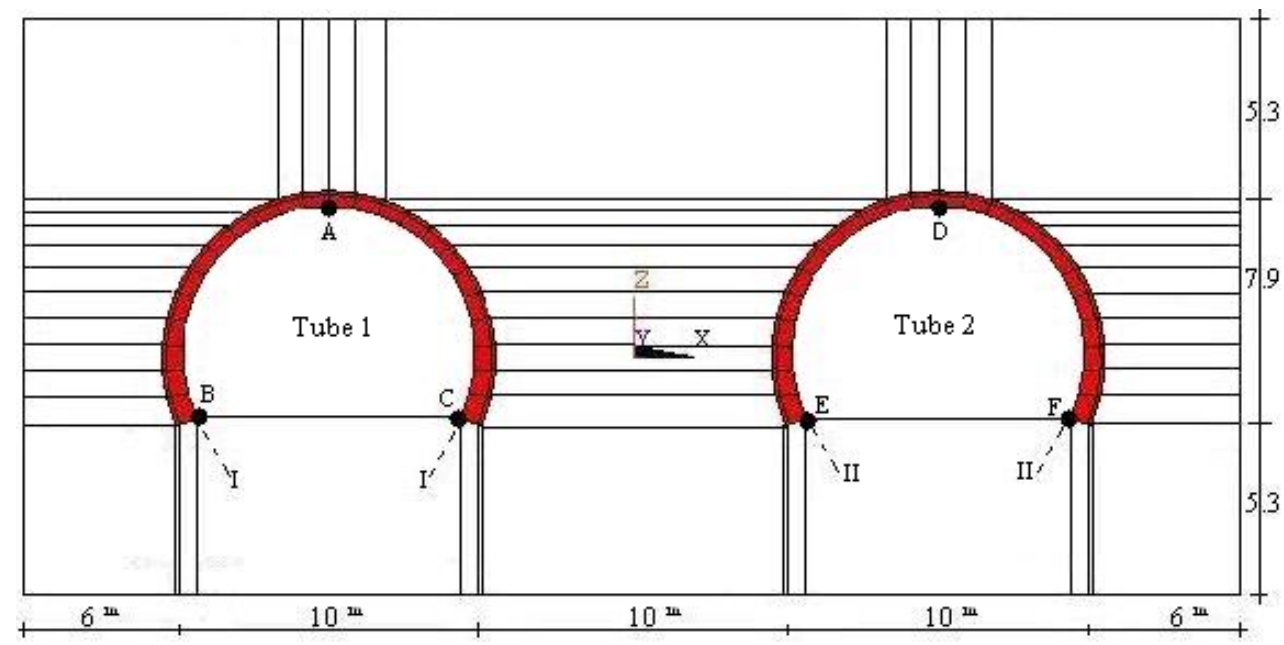

Fig. 6. Location of presented nodes, I-I and II-II sections on the Arhavi Highway Tunnel.

The time histories of displacements and principal stresses on nodes such as A, B, C, D, E, and F (Fig. 6) are the results of the nonlinear transient analyses of the Arhavi Highway Tunnel; additionally, the variations in the lateral displacements along to I-I and II-II sections (Fig. 6), the displacements and the stresses contour diagrams are obtained.

\subsubsection{Displacements}

The maximum horizontal and vertical displacement contours of the tunnel are presented in Fig. 7a, b, respectively. These contours represent the distribution of the peak values reached by the maximum displacement at each point within the section. It can be seen from Fig. 8a that the maximum horizntal displacements occur at the bases of the tunnel. The maximum vertical displacements occur at nearly the half height of the tunnel as seen in Fig. 8b. In addition, the vertical displacements have a symmetric distribution on both models. However, the both of horizontal and vertical displacements are too small to make damage in the tunnel.

Figure $8 \mathrm{a}, \mathrm{b}$ shows the variation of maximum horizontal displacements (x direction - Fig. 6) on I-I section (Tube 1) and II-II section (Tube 2) of the Arhavi Highway Tunnel, respectively. As it can be seen from Fig. 8, there is not a regular distribution along the I-I and II-II sections, however, the graphs (a) and (b) are almost closed to eachother. This 


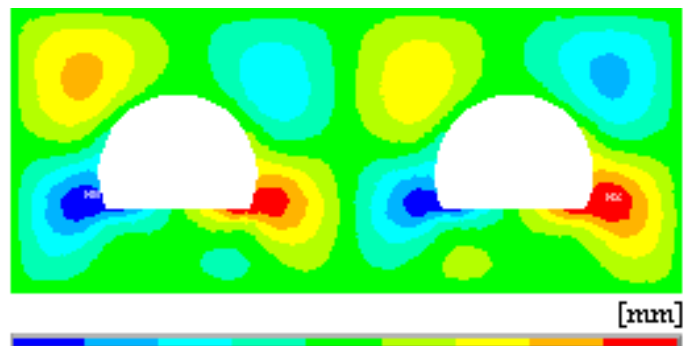

$\begin{array}{llllllllll}-1.2 & -1.0 & -0.7 & -0.4 & -0.1 & 0.1 & 0.4 & 0.7 & 1.0 & 1.2\end{array}$

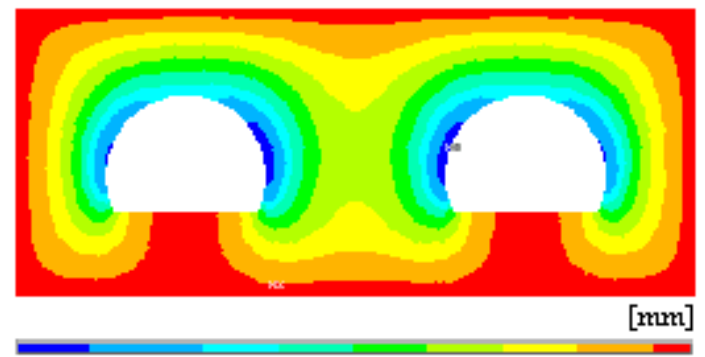

\begin{tabular}{lllllllllll}
\hline 8.3 & -7.4 & -6.5 & -5.5 & -4.6 & -3.7 & -2.8 & -1.9 & -0.9 & 0.0
\end{tabular}

(b) Vertical displacement contour

Fig. 7. The maximum (a) horizontal and (b) vertical displacement contours of the Arhavi Highway Tunnel.

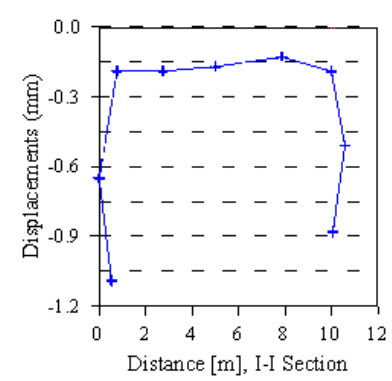

(a) The displacements on I-I section

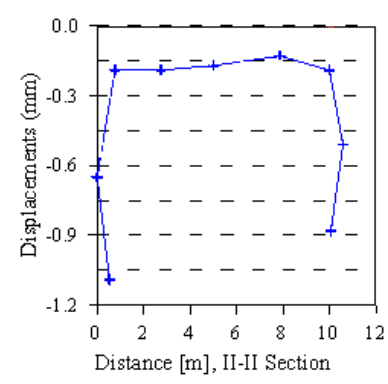

(b) The displacements on II-II sectio
Fig. 8. The variation of maximum horizontal displacements on (a) I-I section (b) II-II section of the Arhavi Highway Tunnel.

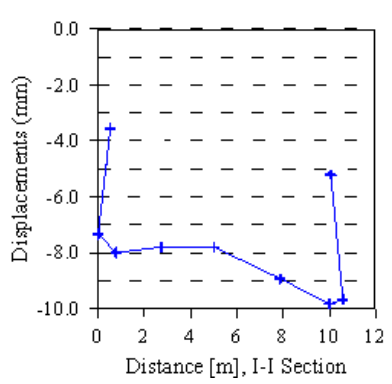

(a) The displacements on I-I section

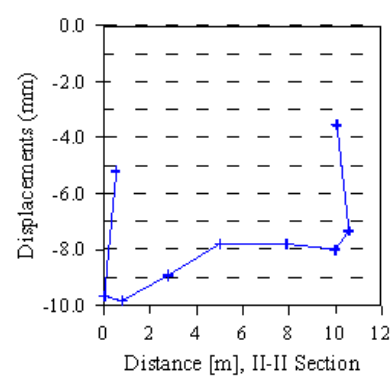

(b) The displacements on II-II sectio:
Fig. 9. The variation of maximum vertical displacements on (a) I-I section (b) II-II section of the Arhavi Highway Tunnel.

shows that both of the tubes behave similarly because of the same geometry and material.

Figure 9a, b shows the variation of maximum vertical displacements (z direction-Fig. 6) on I-I section (Tube 1) and II-II section (Tube 2) of the Arhavi Highway Tunnel, respectively. As it can be seen from Fig. 9, the vertical displacements are low at the bases of the tubes when compared to middle parts of the tubes. In addition, the vertical

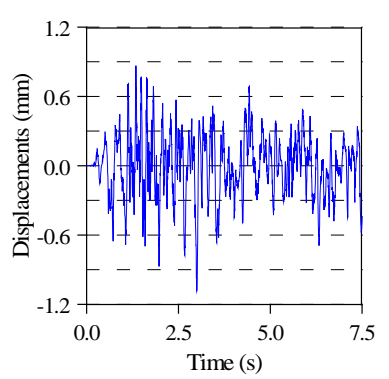

(a) Displacements of Node B

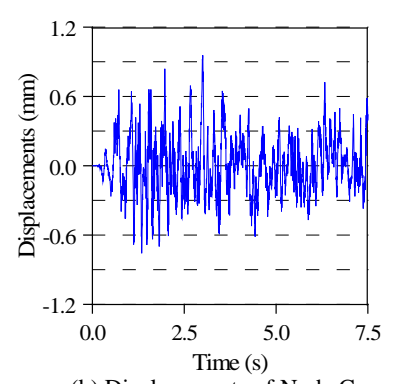

(b) Displacements of Node C
Fig. 10. The time histories of horizontal displacements at (a) Node $\mathrm{B}$ and (b) Node $\mathrm{C}$ of the Arhavi Highway Tunnel.

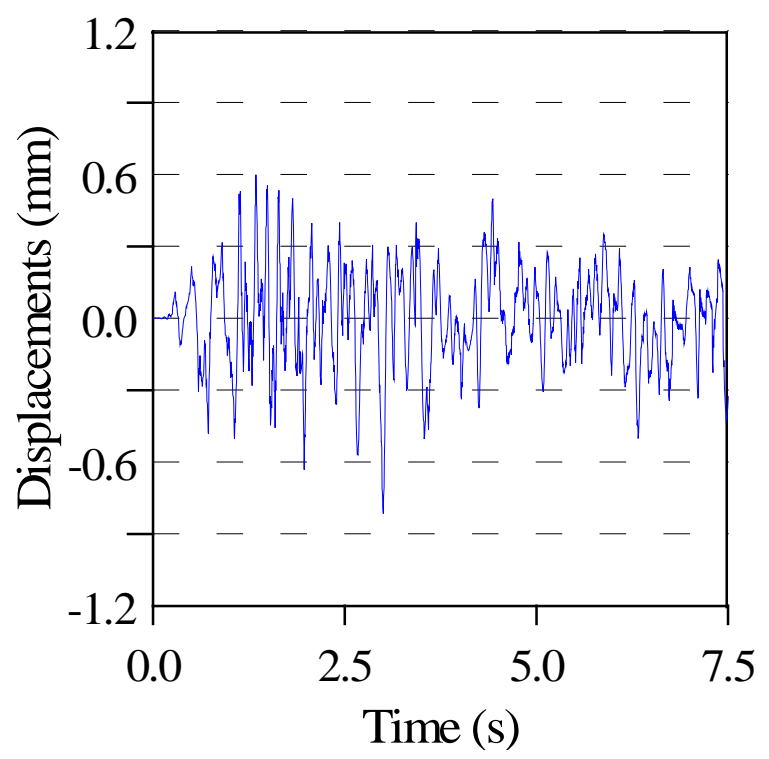

Fig. 11. The time histories of vertical displacements at Node A of the Arhavi Highway Tunnel. 


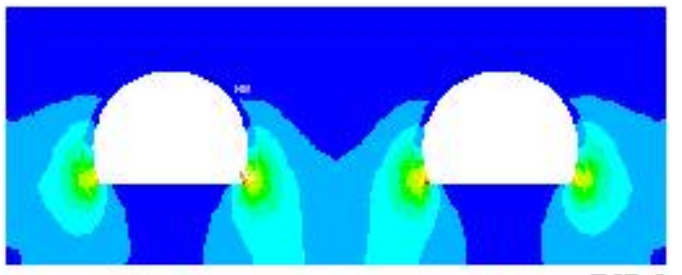

$[\mathrm{MPa}]$

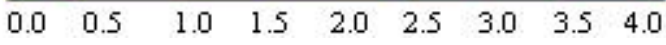

(a) Maximum principal stress contour

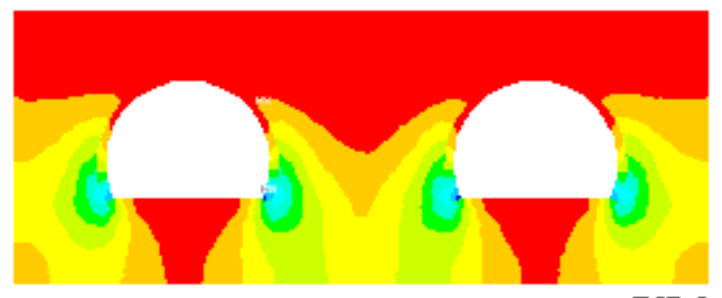

$[\mathrm{MPa}]$

$\begin{array}{llllllllll}-6.0 & -5.6 & -4.8 & -4.2 & -3.7 & -3.1 & -2.2 & -1.7 & -0.8 & 0.0\end{array}$

(b) Minimum principal stress contour

Fig. 12. (a) Maximum and (b) Minimum principal stress contours of the Arhavi Highway Tunnel.

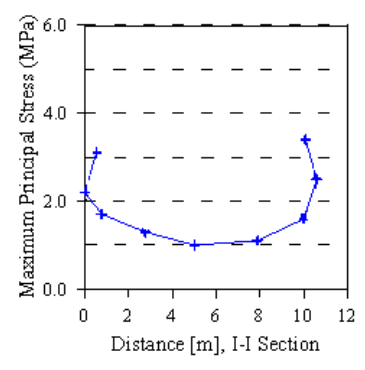

(a) The maximum stresses on I-I section

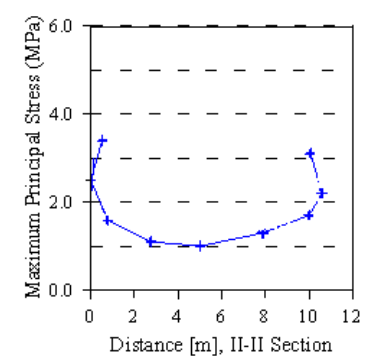

(b) The maximum stresses on II-II sectiol
Fig. 13. The variation of maximum principal stresses on (a) $I-I$ section (b) II-II section of the Arhavi Highway Tunnel.

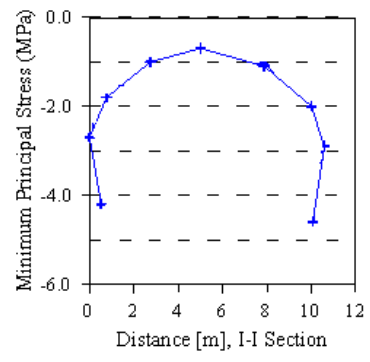

(a) The minimum stresses on I-I section

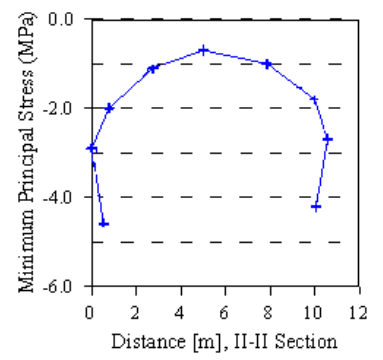

(b) The minimum stresses on II-II sectioI
Fig. 14. The variation of minimum principal stresses on (a) $I-I$ section (b) II-II section of the Arhavi Highway Tunnel.

displacements obtained for the I-I section (Tube 1) and II-II section (Tube 2) have a symmetrical distribution.

When compared to horizontal and vertical displacements from Figs. 8 and 9 that maximum horizontal displacements occur on Nodes B, C, E and F. However maximum vertical displacements occur on the middle height nodes of the tunnel. This shows that the tunnel has a horizontal motion at the base nodes; however it has a vertical motion near to the middle nodes.

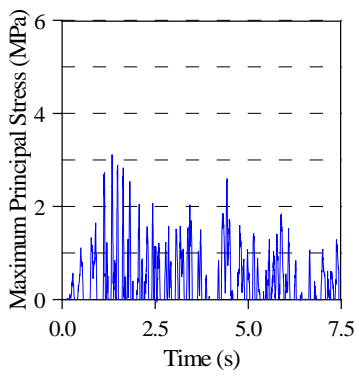

(a) Maximum stresses of Node B

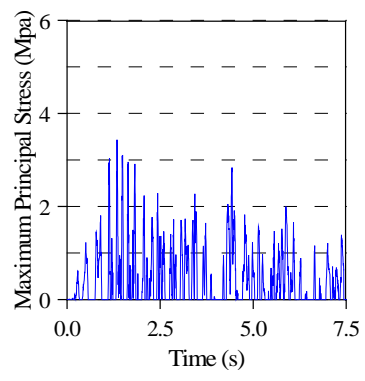

(b) Maximum stresses of Node C
Fig. 15. The time histories of maximum principal stresses at (a) Node B and (b) Node C of the Arhavi Highway Tunnel.

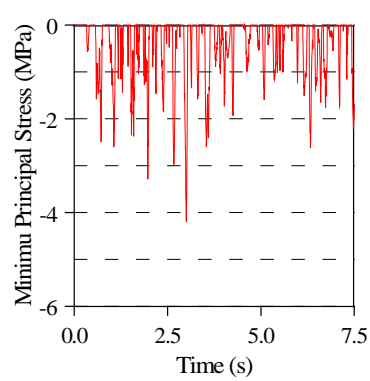

(a) Minimum stresses of Node B

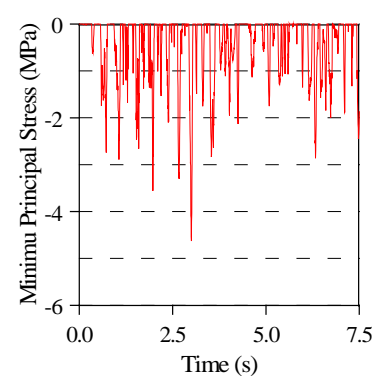

(b) Minimum stresses of Node C
Fig. 16. The time histories of minimum principal stresses at (a) Node B and (b) Node C of the Arhavi Highway Tunnel.

The time histories of horizontal displacements at the nodal points $\mathrm{B}$ and $\mathrm{C}$ of the tunnel (Fig. 6), where the maximum horizontal displacements occurred, are plotted in Fig. 10a, b, respectively. The time histories of vertical displacements at the nodal point A of the tunnel are plotted in Fig. 11. 


\subsubsection{Principal stresses}

The maximum and minimum principal stress contours of the tunnel are presented in Fig. 12a, b, respectively. These represent the distribution of the peak values reached by the maximum stresses at each point within the section. As it is seen from Fig. 12, maximum and minimum principal stresses occur at the bases of the tunnel. In addition, the stresses have a symmetrical distribution along the sections. Also, the maximum stresses are about 3.5-4.0 MPa, the minimum stresses are about $6.0-4.5 \mathrm{Mpa}$. The maximum and minimum principal stress values in the tunnel can be an acceptable level compared to the strength of the concrete during the earthquakes.

Figure 13a, $b$ shows the variation of maximum principal stresses on I-I section (Tube 1) and II-II section (Tube 2) of the Arhavi Highway Tunnel, respectively. As it can be seen from Fig. 13, the maximum stresses are low at the top of the tunnel; however they are high at the bases. The stresses obtained for the I-I section (Tube 1) and II-II section (Tube 2) have a symmetrical distribution.

Figure $14 \mathrm{a}, \mathrm{b}$ shows the variation of minimum principal stresses on I-I section (Tube 1) and II-II section (Tube 2) of the Arhavi Highway Tunnel, respectively. As it can be seen from Fig. 14, the minimum stresses have a symmetrical distribution like the maximum principal stresses.

When comparing the maximum and minimum principal stresses from Figs. 13 and 14, we find that both of highest stresses occur on Nodes B, C, E and F. This shows that the tunnel has the highest forcing at the base nodes.

The time histories of maximum principal stresses at the nodal points $\mathrm{B}$ and $\mathrm{C}$ of the tunnel (Fig. 6), where the maximum horizontal displacements occurred, are plotted in Fig, 15a, b, respectively. The time histories of minimum principal stresses at the nodal point A of the tunnel are plotted in Fig. 16a, b. There are little differences in the frequency content of the both nodes.

\section{Conclusions}

This paper investigates nonlinear earthquake behaviour of the Arhavi Highway Tunnel considering foundation-structure interaction. A Finite Element Model of the tunnel is modelled using ANSYS software and the earthquake behaviour of the tunnel is investigated using 1992 Erzincan, Turkey ground motion records. In this study, the author noted the fallowing observations:

- The first eight natural frequencies obtained from the FEM of the Arhavi Highway Tunnel occur in the range of $224-320 \mathrm{~Hz}$. The observed mode shapes within this frequency range can be basically arranged as bending modes. Maximum displacements occur as $1.1 \mathrm{~mm}$ and $0.6 \mathrm{~mm}$, respectively from earthquake analyses of the
FEM of the tunnel. The displacement levels correspond to less than $1 \%$ of the thickness of the tunnel.

- The horizontal displacements are the highest at the base nodes, and the vertical displacements are the middle height nodes of the tunnel.

- The maximum and minimum principal stresses occur as $3.43 \mathrm{MPa}$ and $4.63 \mathrm{MPa}$, respectively from nonlinear transient analyses of the Arhavi Highway Tunnel. The principal stress values in the tunnel can be the acceptable strength of the concrete during the earthquakes. Both maximum and minimum principal stresses generally occur at regions around the base of the tunnel.

- The Arhavi Tunnel has a nearly symmetrical geometry; hence, the displacements and stresses obtained from one of the tubes are very near to the other tube's results.

Acknowledgements. The author extends his thanks to Ömer Fettahoğlu, who is an engineer in the Cengiz Project, for his logistical assistance.

Edited by: M. E. Contadakis

Reviewed by: two anonymous referees

\section{References}

Amberg, W. and Russo, M.: Seismic design of underground structures - the Bolu Tunnel, Proceedings of the AITES-ITA 2001 World Tunnel Congress, Milano, Italy, 1, 137-147, 2001.

ANSYS: Swanson Analysis System, USA, 2010.

Asakura, T., Tsukada, K., Matsunaga, T., Matsuoka, S., Yashiro, K., Shiba, Y., and Oya, T.: Damage to mountain tunnels by earthquake and its mechanism, Proceedings of JSCE (Japan Society of Civil Engineers) 659, 27-38, 2000.

Barla, G., Bonini, M., and Debernardi, D.: Time depended deformations in squeezing tunnels. The 12th International Conference of International Association of Computer Methods and Advances in Geomechanics, 1-6 October, 1-11, Goa, India, 2008.

Bathe, K. J.: Finite Element Procedures in Engineering Analysis. Prentica Hall: Englewood Cliffs, NJ, 1996.

Cengiz Project: Cengiz Project, Black Sea Coast Road Project, Artvin, Turkey, 2006.

Chen, W. F. and Mizuno, E.: Nonlinear Analysis in Soil Mechanics, Elsevier Science Publishers B. V., Amsterdam, Netherlands, 1990.

Cheng, C. Y., Dasari, G. R., Chow, Y. K., and Leung, C. F.: Finite element analysis of tunnel-soil-pile interaction using displacement controlled model, Tunn. Undergr. Sp. Tech., 22, 450-466, 2007.

Dowding, C. H. and Rozen, A.: Damage to rock tunnels from earthquake shaking, J. Geotech. Eng.-ASCE, 104 (GT2), 175-191, 1978.

Drucker, D. C. and Prager, W.: Soil mechanics and plastic analysis on limit design, Quart. J. Appl. Math., 10, 157-165, 1952.

G.D.H.: General Directorate of Highways, Republic of Turkey, Ankara, Turkey, 2006. 
Hashash, Y. M. A., Hook, J. J., and Schmid, J. I. C.: Seismic design and analysis of underground structures, Tunn. Undergr. Sp. Tech., 16, 247-293, 2001.

Kolymbas, D.: Tunelling and Tunnel Mechanics: A Rational Approach to Tunneling, Springer-Verlag Berlin Heidelberg, Germany, 2005.

Lanzano, G., Bilotta, E., and Russo, G.: Seismic soil-tunnelstructure interaction analysis and retrofit of the Posey-Webster Street Tunnels, The 2nd UJNR Workshop on Soil-Structure Interaction, Tsukuba, Japan, 2001.

Mroueh, H. and Shahrour, I.: A simplified 3D model for tunnel construction using tunnel boring machines, Tunn. Undergr. Sp. Tech., 23, 38-45, 2008.
PEER: (Pacific Earthquake Engineering Research Center), http:// peer.berkeley.edu/smcat/data, 10 July 2010.

Satır, B.: Determining Deformations of Tunnel with Geodetic, Geotechnical and Finite Element Method, MSc Thesis, Karadeniz Technical University, Trabzon, Turkey, 2007 (in Turkish).

St. John, C. M. and Zahrah, T. F.: A seismic design of underground structures, Tunn. Undergr. Sp. Tech., 2, 165-197, 1987.

USACE: Time-History Dynamic Analysis of Concrete Hydraulic Structures, Engineering and Design, USA, 2003. 